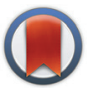

CrossMark

\&lick for updates

Cite this: Polym. Chem., 2016, 7, 3370

Received 10th March 2016, Accepted 23rd April 2016

DOI: 10.1039/c6py00426a

www.rsc.org/polymers

\section{Styrenic DABCO salt-containing monomers for the synthesis of novel charged polymers $\dagger$}

\author{
Keren Zhang, Kevin J. Drummey, Nicholas G. Moon, William D. Chiang and \\ Timothy E. Long*
}

\begin{abstract}
A facile, two-step synthesis afforded styrenic DABCO salt monomers bearing two cyclic quaternary ammonium cations. Free radical polymerization of the DABCO salt monomers yielded homopolymers and copolymers with $n$-butyl acrylate. DABCO saltcontaining ionomers exhibited superior thermomechanical properties with extended plateau regimes compared to ionomers bearing singly-charged pendant groups.
\end{abstract}

Ion-containing polymers represent one of the largest families of functional polymers, and this field continues to expand due to critical commercial technologies, including water treatment, fuel cell membranes, filtration membranes, adhesives, biosensors, gene delivery, antimicrobial materials, and biomedical materials. ${ }^{1-7}$ The synthesis of ion-containing polymers generally utilizes either polymerization of ionic monomers or post-functionalization of neutral polymers. Direct polymerization of charged monomers generally provides better tunability regarding ion type, concentration, and distribution within the main chain. For example, polymerizable ionic liquids, a family of charged monomers with melting points lower than $100{ }^{\circ} \mathrm{C}$, have received significant attention over the past decade. ${ }^{8}$ Common ionic groups include, but are not limited to: ammoniums, phosphoniums, imidazoliums, sulfonates, carboxylates, and phosphates. Most polymerizable ionic monomers carry a single cation/anion with an electrostatically bonded counterion, and the effect of singly-charged monomer incorporation on polymer properties is well described..$^{9-11}$

Monomers carrying multiple charges recently emerged as interesting candidates for the design of ion-containing polymers. ${ }^{12,13}$ For example, a zwitterionic monomer generally contains a single covalently linked ion pair, and affords stronger association compared to singly-charged analogues, inducing more well-defined microphase-separation and superior

Department of Chemistry, Macromolecules Innovation Institute, Virginia Tech, Blacksburg, VA 24061, USA.E-mail: telong@vt.edu

$\dagger$ Electronic supplementary information (ESI) available: Full experimental procedures and additional characterization data. See DOI: 10.1039/c6py00426a mechanical properties. ${ }^{14}$ However, only a few reports describe ionic monomers that contain two chemically bound cations or anions. Li et al. synthesized a polyelectrolyte with bis(trialkyl ammonium) acrylate, which displayed a lower critical aggregation value and larger aggregate sizes than the singly-charged analogues at similar charge concentrations. Quaternization of a cyclic diamine, 1,4-diazabicyclo[2.2.2]octane (DABCO), yields a doubly charged group. Salamone and Snider first synthesized DABCO based ionones using polyaddition of DABCO and dibromoalkane. ${ }^{15}$ Others reported DABCO double ammonium salt (abbreviated as DABCO salt)-containing monomers for free radical polymerization. Dizman et al. demonstrated the antimicrobial properties of DABCO salt-containing polyelectrolytes. ${ }^{16}$ Kopchinski also synthesized DABCO salt-containing polyelectrolytes for removal of phosphates from waste water. ${ }^{17}$ Previous reports of these doubly-charged monomers involved complex synthetic routes, and earlier examples of the corresponding polymers mainly focused on polyelectrolytes from charged homopolymers. This manuscript introduces a facile synthetic route to access a library of DABCO salt-containing. monomers, and corresponding homopolymers and copolymers. Characterization of doubly-charged copolymers focuses on ionomers with relatively low ionic content. Styrenic triethylammonium monomers served as singly-charged controls. Thermal characterization suggested similar thermal stability and thermal transitions of DABCO salt-containing copolymers compared to the singly-charged analogues. However, dynamic mechanical analysis (DMA) revealed distinctively different thermomechanical performance for DABCO salt-containing copolymer films compared to singly-charged analogues.

Herein, we describe an efficient synthetic strategy to access a library of $N$-4-vinylbenzyl- $N$-alkyl DABCO $\mathrm{BrCl}\left(\mathrm{VBDC}_{x} \mathrm{BrCl}\right)$ monomers. Two sequential nucleophilic substitutions yielded a series of $\mathrm{VBDC}_{x} \mathrm{BrCl}$ monomers with varying alkyl substituents (Scheme 1). In the first step, DABCO reacted with a 1-bromoalkane to form a mono-alkylated intermediate in the absence of the di-alkylated impurity. Careful solvent selection enabled precipitation of this intermediate, and the remaining tertiary amine proved less reactive than the amines before 


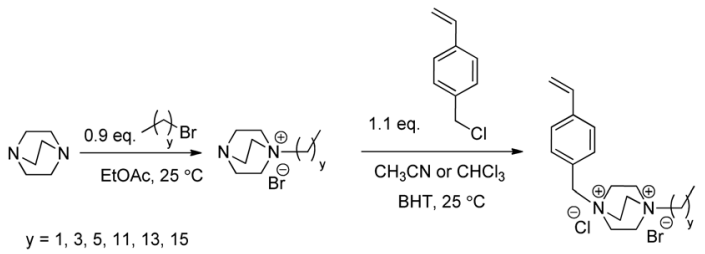

Scheme 1 Synthesis of $N$-4-vinylbenzyl- $N$-alkyl $\quad \mathrm{DABCO}-\mathrm{BrCl}$ $\left(\mathrm{VBDC}_{x} \mathrm{BrCl}\right)$ monomer library, $(x=y+1)$.

alkylation due to the nearby electron-withdrawing ammonium, which prevented the second alkylation from occurring. The subsequent reaction between the intermediate and 4-vinylbenzyl chloride $(4 \mathrm{VBCl})$ yielded $\mathrm{VBDC}_{x} \mathrm{BrCl}$ monomers. The reaction solvent again dissolved the starting materials and allowed the product to precipitate, which eased purification. Monomer synthesis proved facile, high-yielding, and suitable for scaleup, with only filtration and washing required for purification. NMR spectroscopy and mass spectroscopy confirmed the chemical structure and purity of all $\mathrm{VBDC}_{x} \mathrm{BrCl}$ monomers in Scheme 1 (Table S1, Fig. S1 and S2 $\dagger$ ). Successful homopolymerization of four representative DABCO salt monomers demonstrated their suitability for free radical polymerization (Scheme 2, Fig. S3†). Triethyl-(4-vinylbenzyl)ammonium chloride (VBTEACl) was synthesized according to Long et al. and used as a singly-charged control. ${ }^{18}$

Among the DABCO salt-containing monomers, $\mathrm{VBDC}_{6} \mathrm{BrCl}$ and $\mathrm{VBDC}_{14} \mathrm{BrCl}$ with hexyl and tetradecyl substituents, respectively, were initially selected for copolymerization. Free radical copolymerization of $n \mathrm{BA}$ and $\mathrm{VBDC}_{6} \mathrm{BrCl} / \mathrm{VBDC}{ }_{14} \mathrm{BrCl}$ yielded copolymers with varying ionic content (Scheme 3, Table 1). A mixture of DMSO and DMF was suitable for polymerization, and efficiently removed through precipitation and drying. It was presumed that ion-containing styrenic and acrylic monomers randomly copolymerized in a manner
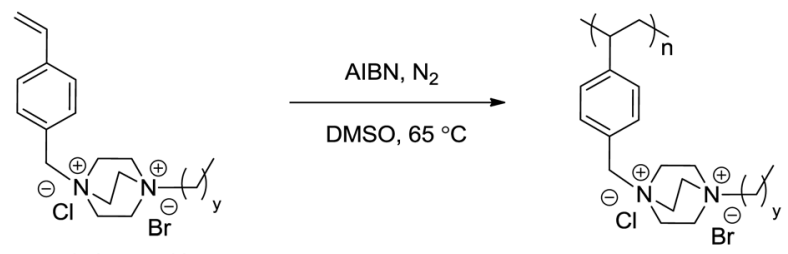

$y=1,3,5$ or 13

Scheme 2 Synthesis of poly $\left(\mathrm{VBDC}_{x} \mathrm{BrCl}\right)$ homopolymers, $(x=y+1)$.

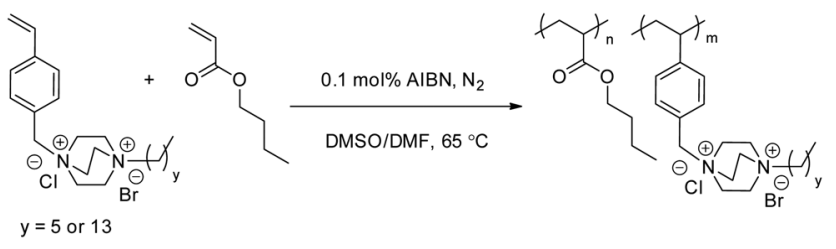

Scheme 3 Synthesis of poly $\left(\mathrm{VBDC}_{6} \mathrm{BrCl}-\mathrm{co}-n \mathrm{BA}\right)$ and poly $\left(\mathrm{VBDC}_{14} \mathrm{BrCl}-\right.$ co- $n \mathrm{BA}$ ) copolymers. similar to styrenics and acrylics. ${ }^{19-21}$ Random copolymers of VBTEACl and $n$ BA with comparable ionic content served as controls for the comparison of doubly-charged ionic groups to their singly-charged analogues (Scheme S2, Table S2 $\dagger$ ). All polymerization conditions remained identical for both DABCO salt-containing copolymers and singly-charged copolymers, including initiator and monomer concentrations, temperature, and reaction time. ${ }^{1} \mathrm{H}$ NMR spectroscopic analysis of the purified copolymers revealed their ionic contents (Fig. S4 and S5†). Integrations of methyl protons on $n \mathrm{BA}$ and aromatic protons on $\mathrm{VBDC}_{x} \mathrm{BrCl}$ (Fig. S4 $\dagger$ ) provided copolymer compositions in Table 1 . The copolymer compositions generally matched the feed ratios at relatively low ionic monomer incorporation. Styrenic content was higher than the feed ratio at relatively high $\mathrm{VBDC}_{x} \mathrm{BrCl}$ incorporation, consistent with previous studies reporting the preferential incorporation of styrenics over acrylics at high styrenic/acrylics feed ratios. ${ }^{19}$ Although schemes depict DABCO salt units with chloride adjacent to the benzyl ammonium and bromide adjacent to the alkyl ammonium, anion exchange may occur in solution.

Thermogravimetric analysis (TGA) under nitrogen revealed the thermal properties of DABCO salt-containing copolymers. Poly $\left(\mathrm{VBDC}_{14} \mathrm{BrCl}-c o-n \mathrm{BA}\right)$, poly $\left(\mathrm{VBDC}_{6} \mathrm{BrCl}-c o-n \mathrm{BA}\right)$, and poly(VBTEACl-co- $n \mathrm{BA})$ displayed two-step weight-loss profiles in TGA temperature ramps (Fig. 1, S6 and S7 $\dagger$ ). Thermal

Table 1 Feed ratios of the ionic monomers and monomer incorporation in polymers for poly $\left(\mathrm{VBDC}_{6} \mathrm{BrCl}-\mathrm{co}-n \mathrm{BA}\right) \mathrm{s}$ and poly $\left(\mathrm{VBDC}_{14} \mathrm{BrCl}-\right.$ co-nBA)s

Ionic monomer content

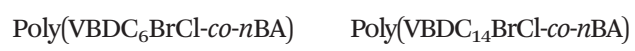

\begin{tabular}{|c|c|c|c|c|}
\hline Feed mol\% & $\begin{array}{l}\text { Observed } \\
\text { mol\% }\end{array}$ & $\begin{array}{l}\text { Observed } \\
\text { wt } \%\end{array}$ & $\begin{array}{l}\text { Observed } \\
\text { mol\% }\end{array}$ & $\begin{array}{l}\text { Observed } \\
\text { wt } \%\end{array}$ \\
\hline 3 & 1 & 5 & 2 & 7 \\
\hline 9 & 12 & 31 & 8 & 28 \\
\hline 17 & 20 & 45 & 20 & 51 \\
\hline 33 & 42 & 70 & 38 & 72 \\
\hline
\end{tabular}

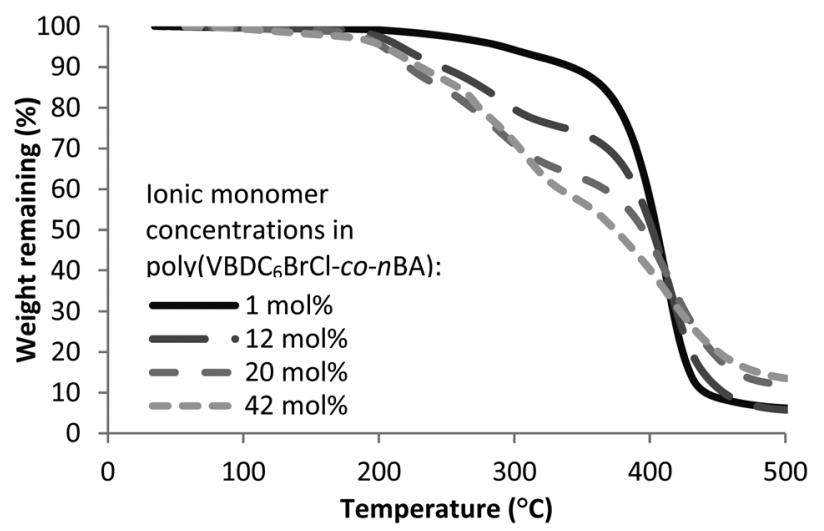

Fig. 1 TGA traces of poly $\left(\mathrm{VBDC}_{6} \mathrm{BrCl}-\mathrm{co}-n \mathrm{BA}\right) \mathrm{s}$ with varying ionic monomer concentrations. 
degradation of ammonium-containing polymers generally occurs from dequaternization of the ammonium. ${ }^{22}$ Long et al. utilized the first-step weight-loss of trialkylammonium polyelectrolytes to determine that their dequaternization followed a nucleophilic degradation pathway. ${ }^{18}$ TGA profiles of poly(VBTEACl-co$n \mathrm{BA}) \mathrm{s}$ (Fig. S7, Table $\mathrm{S} 4 \dagger$ ) suggested a similar degradation mechanism. However, thermal degradation of DABCO saltcontaining copolymers proved more complex as the DABCO salt contained both benzylic and aliphatic ammoniums. Dequaternization of both ammonium cations occurred together in the first weight-loss step.

The dequaternization mechanism of the alkyl-substituted ammonium remained unclear without further analysis as both nucleophilic substitution and Hofmann elimination pathways would result in the same weight-loss (Scheme 4). Dequaternization of the ammonium adjacent to the benzyl group predominantly followed a reverse nucleophilic substitution mechanism (Scheme 5), as evidenced from the weight-loss of the first step. Table 2 summarizes theoretical weight-loss

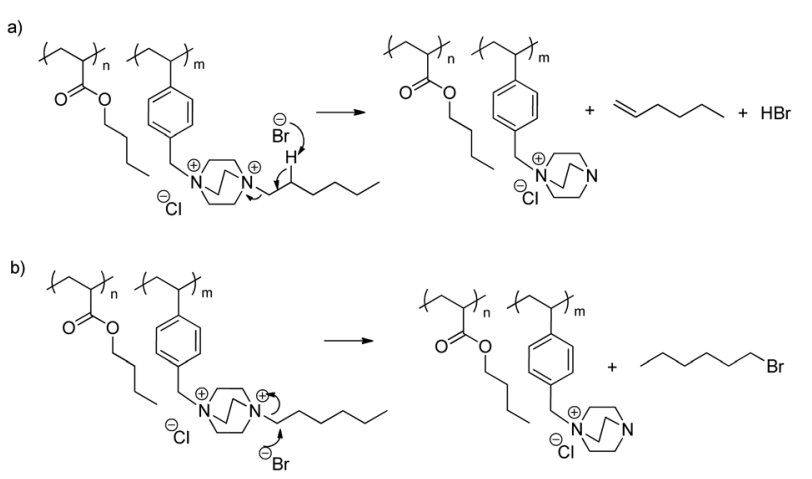

Scheme 4 Dequaternization of the alkyl-substituted ammonium through (a) nucleophilic substitution and (b) Hofmann elimination.

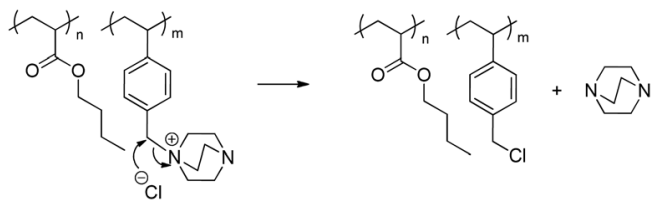

Scheme 5 Dequaternization of the benzyl-substituted ammonium through nucleophilic substitution. of poly $\left(\mathrm{VBDC}_{6} \mathrm{BrCl}-\mathrm{co}-n \mathrm{BA}\right)$, calculated from both Hofmann elimination and nucleophilic substitution pathways for the benzyl ammonium (Scheme 5, S3a $\dagger$ ). Weight-loss of the first degradation step compared closely with calculations for the nucleophilic pathway of the benzyl ammonium degradation. The second weight-loss step corresponded to the polymer backbone degradation. The char residue generally increased with increasing styrenic contents in the copolymers. TGA profiles of poly(VBDC $\left.{ }_{14} \mathrm{BrCl}-c o-n \mathrm{BA}\right) \mathrm{s}$ showed a similar result (Fig. S6, Scheme S3b, Table S3†). The $5 \mathrm{wt} \%$ loss temperature values $\left(T_{\mathrm{d}}\right)$ of DABCO salt-containing copolymers ranged from $190{ }^{\circ} \mathrm{C}$ to $290{ }^{\circ} \mathrm{C}$, similar to $T_{\mathrm{d}}$ values of poly(VBTEACl-co- $\left.n \mathrm{BA}\right)$ $\mathrm{s}$ (Table 2, S3 and $\mathrm{S} 4 \dagger$ ). $T_{\mathrm{d}}$ values in each series decreased with increasing ionic content due to a decrease of the more thermally stable acrylic content.

Differential scanning calorimetry (DSC) revealed similar thermal transitions when comparing DABCO salt-containing polymers to their singly-charged analogues (Fig. S8-10, Table S5†). All ion-containing homopolymers and copolymers were amorphous. For homopolymers of poly $\left(\mathrm{VBDC}_{14} \mathrm{BrCl}\right)$, poly $\left(\mathrm{VBDC}_{6} \mathrm{BrCl}\right)$, and poly $(\mathrm{VBTEACl})$, DSC failed to detect any glass transition temperature $\left(T_{\mathrm{g}}\right)$ below their thermal degradation temperatures. Copolymers with lower than $25 \mathrm{~mol} \%$ ionic monomer each exhibited a single $T_{\mathrm{g}}$ in the range from $-45{ }^{\circ} \mathrm{C}$ to $-36^{\circ} \mathrm{C}$, attributed to long range segmental motion of the polynBA soft phase (homopolymer $T_{\mathrm{g}}-47^{\circ} \mathrm{C}$ ). The mild $T_{\mathrm{g}}$ increase $\left(<10{ }^{\circ} \mathrm{C}\right)$ with increasing ionic content resulted from the ionic association of DABCO salt restricting adjacent chain mobility.

Poly(VBDC ${ }_{x}$ BrCl-co- $\left.n \mathrm{BA}\right)$ and poly(VBTEACl-co- $\left.n \mathrm{BA}\right)$ with $3 \mathrm{~mol} \%$ or less ionic monomer were tacky solids. Copolymers with $8 \mathrm{~mol} \%$ or more ionic monomer were solution cast into free-standing films. Charged styrenic monomers contributed both a high $T_{\mathrm{g}}$ component and ionic associations that largely enhanced the mechanical properties of the polynBA matrix. DMA revealed biphasic thermomechanical behavior of DABCO salt-containing copolymers with relatively low ionic contents ( $\leq 15 \mathrm{~mol} \%$ ), consistent with typical ionomers (Fig. 2). ${ }^{9,23}$ However, the unprecedented wide and well-defined plateau window of DABCO salt-containing films indicated superior microphase-separation and stronger ionic interactions of the DABCO salt units compared to other ionomers with zwitterions or singly-charged ions. ${ }^{14,24-26}$ Fig. 2 compares storage moduli and tan delta of two ionomers films with similar incorporations of $\mathrm{VBDC}_{6} \mathrm{BrCl}$ and VBTEACl. The poly(VBTEACl-co-

Table 2 Temperatures at $5 \%$ weight-loss and correlation of initial thermal weight-loss of poly(VBDC $\left.{ }_{6} \mathrm{BrCl}-\mathrm{co}-n \mathrm{BA}\right) \mathrm{s}$ to a nucleophilic substitution or Hofmann elimination degradation pathway for the benzyl ammonium degradation

\begin{tabular}{|c|c|c|c|c|c|}
\hline $\begin{array}{l}\mathrm{VBDC}_{6} \mathrm{BrCl} \\
\mathrm{mol} \%\end{array}$ & $\begin{array}{l}\mathrm{VBDC}_{6} \mathrm{BrCl} \\
\mathrm{wt} \%\end{array}$ & $\begin{array}{l}T_{\mathrm{d}, 5 \mathrm{wt} \%} \\
\left({ }^{\circ} \mathrm{C}\right)\end{array}$ & $\begin{array}{l}\text { Observed weight-loss } \\
1^{\text {st }} \text { step (\%) }\end{array}$ & $\begin{array}{l}\text { Theoretical weight-loss } \\
1^{\text {st }} \text { step Nu (\%) }\end{array}$ & $\begin{array}{l}\text { Theoretical weight-loss } \\
1^{\text {st }} \text { step Hofmann (\%) }\end{array}$ \\
\hline 1 & 5 & 291 & 4 & 3 & 2 \\
\hline 20 & 45 & 203 & 35 & 29 & 19 \\
\hline 42 & 70 & 204 & 42 & 45 & 28 \\
\hline
\end{tabular}




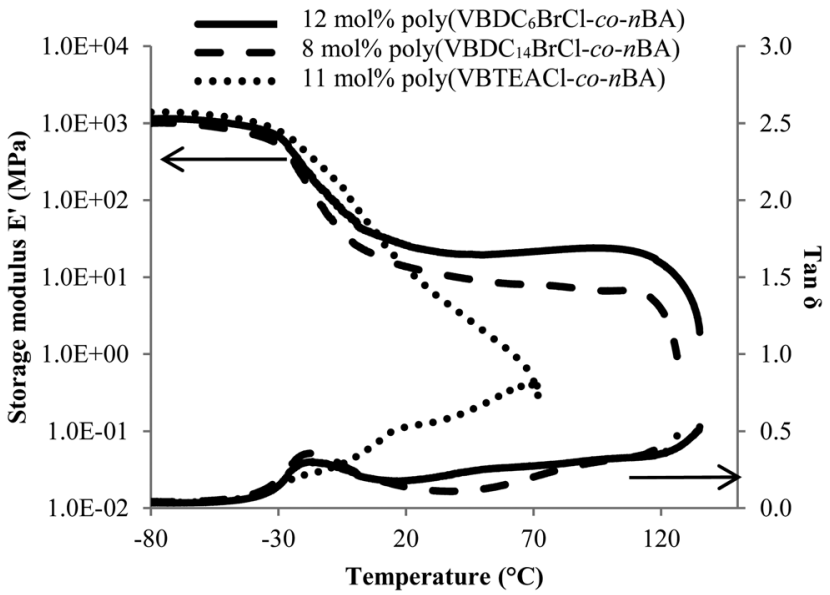

Fig. 2 Dynamic mechanical temperature analysis of poly $\left(\mathrm{VBDC}_{6} \mathrm{BrCl}-\right.$ co- $n \mathrm{BA})$ with $12 \mathrm{~mol} \%$ of $\mathrm{VBDC}_{6} \mathrm{BrCl}$, poly $\left(\mathrm{VBDC}_{14} \mathrm{BrCl}-\mathrm{co}-n \mathrm{BA}\right)$ with $8 \mathrm{~mol} \%$ of $\mathrm{VBDC}_{14} \mathrm{BrCl}$, and poly(VBTEACl-co-nBA) with $11 \mathrm{~mol} \%$ of VBTEACl.

$n \mathrm{BA})$ film showed a broad glass transition, where modulus gradually decreased with increasing temperature until sample yielded. Absence of a plateau window indicated significant phase-mixing in the VBTEACl-containing copolymer film. The significant flow region difference suggested that the singlycharged control afforded weaker ionic interactions compared to the DABCO salt-containing copolymer at similar ionic content.

The first storage modulus drop of poly $\left(\mathrm{VBDC}_{6} \mathrm{BrCl}-c o-n \mathrm{BA}\right)$ and poly $\left(\mathrm{VBDC}_{14} \mathrm{BrCl}-c o-n \mathrm{BA}\right)$ corresponded to the glass transition of the soft phase, composed mainly of polynBA. A welldefined plateau followed the soft phase $T_{\mathrm{g}}$ for each DABCO salt-containing films, during which the storage modulus remained constant with increasing temperature. DABCO salt units associated with each other and formed ionic aggregates, which provided multifunctional physical crosslinking. ${ }^{23,27}$ These physical crosslinks provided mechanical strength for ionomer films during the plateau window. The second modulus drop above $120{ }^{\circ} \mathrm{C}$ was attributed to motion within the ionic aggregates and dissociation of the ionic interactions according to Weiss et al. ${ }^{23}$ Two distinct transitions before and after the plateau region originated from relaxation of polymer chains in the neutral, low $T_{\mathrm{g}}$ phase and the ionic interactions in the ion-rich phase, respectively. The DMA profiles of poly $\left(\mathrm{VBDC}_{6} \mathrm{BrCl}-c o-n \mathrm{BA}\right)$ and poly $\left(\mathrm{VBDC}_{14} \mathrm{BrCl}-c o-n \mathrm{BA}\right)$ ionomer films suggested a well-defined phase-separation with strong ionic interaction. ${ }^{9,19}$ Thermomechanical analysis revealed that DABCO salt units were more efficient than singly-charged analogues in forming physical crosslinks and enhancing mechanical performance of an ion-containing copolymer. A forthcoming publication will discuss in greater detail the differences in mechanical, morphological, and rheological properties of DABCO salt-containing copolymers vs. singlycharged controls, as well as the influence of alkyl substituent length and counterion selection.

\section{Conclusions}

We report a facile, two-step synthesis for a library of polymerizable, styrenic DABCO salt monomers. Free radical polymerization afforded DABCO salt-containing homopolymers. Two DABCO salt-containing monomers with hexyl and tetradecyl substituents each yielded a series of copolymers with $n$-butyl acrylate using varying feed ratios of ionic and neutral monomers. DABCO salt-containing copolymers exhibited similar thermal stability and degradation pathway compared to the triethylammonium controls. DABCO salt incorporation into a low $T_{\mathrm{g}}$ acrylic matrix resulted in a physically crosslinked network with ionic interactions. DABCO salt-containing ionomers formed free-standing films and exhibited biphasic thermomechanical properties with unprecedented well-defined plateau windows. Superior thermomechanical performance of DABCO salt-containing copolymers suggested that DABCO salt units afforded significantly stronger ionic interactions and better microphase-separation comparing to the singly-charged analogues. The library of DABCO salt monomers with tunable solubility allows facile synthesis of various ion-containing polymers. DABCO salt-containing ionomers enable applications as elastomers and thermoplastics with superior thermal resistance and processability.

The authors acknowledge Henkel Corporation for financial support and insightful discussions with Dr Charles Paul, Dr Eric Silverberg, and Dr Cristina DeJesus. We also thank $\mathrm{Mr}$ Motohiro Aiba from Tokyo Institute of Technology for his assistance with polymer synthesis.

\section{References}

1 B. Bolto and J. Gregory, Water Res., 2007, 41, 2301-2324.

2 M. A. Hickner, Mater. Today, 2010, 13, 34-41.

3 G. Couture, A. Alaaeddine, F. Boschet and B. Ameduri, Prog. Polym. Sci., 2011, 36, 1521-1557.

4 G. Merle, M. Wessling and K. Nijmeijer, J. Membr. Sci., 2011, 377, 1-35.

5 S. R. Williams and T. E. Long, Prog. Polym. Sci., 2009, 34, 762-782.

6 K. Zhang and T. E. Long, WO, 2015058137A3, 2015.

7 P. G. Lawrence and Y. Lapitsky, Langmuir, 2015, 31, 15641574.

8 D. Mecerreyes, Prog. Polym. Sci., 2011, 36, 1629-1648.

9 M. R. Tant, K. A. Mauritz and G. L. Wilkes, Ionomers: synthesis, structure, properties, and applications, Blackie Academic \& Professional, New York, London, 1997.

10 M. Pineri and A. Eisenberg, Structure and properties of ionomers, Springer Science \& Business Media, 2012.

11 A. Eisenberg and M. King, Ion-containing polymers: physical properties and structure, Academic Press, New York, 1977.

12 A. Laschewsky, Polymers, 2014, 6, 1544-1601.

13 F. Xuan and J. Liu, Polym. Int., 2009, 58, 1350-1361.

14 T. Wu, F. L. Beyer, R. H. Brown, R. B. Moore and T. E. Long, Macromolecules, 2011, 44, 8056-8063. 
15 J. C. Salamone and B. Snider, J. Polym. Sci., Part A: Polym. Chem., 1970, 8, 3495-3501.

16 B. Dizman, M. O. Elasri and L. J. Mathias, J. Appl. Polym. Sci., 2004, 94, 635-642.

17 A. F. Kopchinski, Doctor of Philoscophy, Kansas State University, 1994.

18 S. T. Hemp, M. Q. Zhang, M. H. Allen, S. J. Cheng, R. B. Moore and T. E. Long, Macromol. Chem. Phys., 2013, 214, 2099-2107.

19 S. Cheng, M. Zhang, T. Wu, S. T. Hemp, B. D. Mather, R. B. Moore and T. E. Long, J. Polym. Sci., Part A: Polym. Chem., 2012, 50, 166-173.

20 F. Ziaee and M. Nekoomanesh, Polymer, 1998, 39, 203-207.
21 C. J. Hawker, E. Elce, J. Dao, W. Volksen, T. P. Russell and G. G. Barclay, Macromolecules, 1996, 29, 2686-2688.

22 S. R. Williams, E. M. Borgerding, J. M. Layman, W. Wang, K. I. Winey and T. E. Long, Macromolecules, 2008, 41, 52165222.

23 R. A. Weiss, J. J. Fitzgerald and D. Kim, Macromolecules, 1991, 24, 1071-1076.

24 M. Gauthier, T. Carrozzella and G. Snell, J. Polym. Sci., Part B: Polym. Phys., 2002, 40, 2303-2312.

25 M. Ehrmann, R. Muller, J. C. Galin and C. G. Bazuin, Macromolecules, 1993, 26, 4910-4918.

26 C. G. Bazuin and A. Eisenberg, J. Chem. Educ., 1981, 58, 938.

27 A. Eisenberg, B. Hird and R. B. Moore, Macromolecules, 1990, 23, 4098-4107. 